This item was submitted to Loughborough's Research Repository by the author.

Items in Figshare are protected by copyright, with all rights reserved, unless otherwise indicated.

\title{
Part shrinkage anomilies from stereolithography injection mould tooling
}

PLEASE CITE THE PUBLISHED VERSION

PUBLISHER

(C) Elsevier

VERSION

VoR (Version of Record)

LICENCE

CC BY-NC-ND 4.0

REPOSITORY RECORD

Harris, Russell A., H.A. Newlyn, Richard J.M. Hague, and Phill M. Dickens. 2019. "Part Shrinkage Anomilies from Stereolithography Injection Mould Tooling". figshare. https://hdl.handle.net/2134/4647. 
This item was submitted to Loughborough's Institutional Repository (https://dspace.lboro.ac.uk/) by the author and is made available under the following Creative Commons Licence conditions.

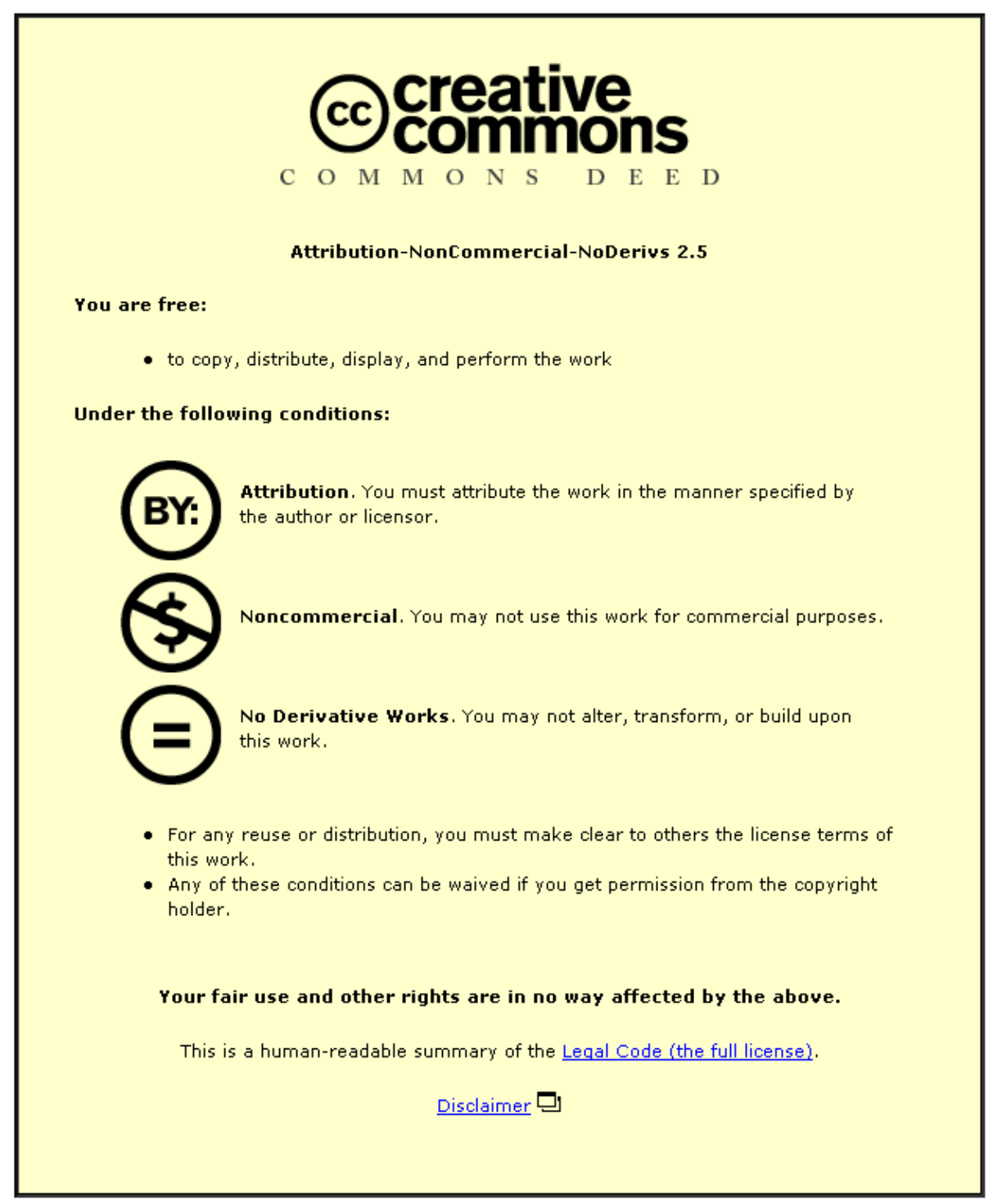

For the full text of this licence, please go to: http://creativecommons.org/licenses/by-nc-nd/2.5/ 


\title{
Part Shrinkage Anomalies from Stereolithography Injection Mould Tooling
}

\author{
R.A.Harris AMIEE* , H.A.Newlyn, R.J.M.Hague AMIMechE \& P.M.Dickens MIEE \\ Wolfson School of Mechanical \& Manufacturing Engineering, \\ Loughborough University, \\ LEICESTERSHIRE, LE11 3TU, UK. \\ *Corresponding Author. E-mail: r.a.harris@lboro.ac.uk \\ Fax: +44 (0) 1509227549
}

\begin{abstract}
The use of stereolithography (SL) tooling allows plastic parts to be produced by injection moulding in a very short time due to the speed of mould production. One of the supposed advantages of the process is that it provides a low volume of parts that are the same as parts that would be produced by the conventional hard tooling in a fraction of the time and cost.

However, this work demonstrates different rates of polymer shrinkage are developed by parts produced by SL and conventional tooling methods. These revelations may counter the greatest advantages of the SL injection moulding tooling process as the parts do not replicate those that would be produced by conventional hard tooling.

This work identifies the different shrinkage that occurs in mouldings produced by an SL mould as compared to those produced from an aluminium mould. The experiments utilise two very different types of polymers and two mould geometries, which are
\end{abstract}


processed in the same manner so that the heat transfer characteristics of the moulds are isolated as the only experimental variable.

The work demonstrates how the two mould materials exhibit very different rates of expansion due to the temperature profiles experienced during moulding. This expansion must be compensated for to establish the total amount of shrinkage incurred by moulded parts. The compensation is derived by a mathematical approach and by modelling using finite element analysis. Both techniques depend upon knowledge of the thermal conditions during moulding. Knowledge of these thermal conditions are obtained by real-time data acquisition and simulated by FEA modeling. The application of the findings provide knowledge of the complete shrinkage values relating to the mould material and polymer used which would enable the production of geometrically accurate parts.

Keywords: Finite Element Analysis, Plastic injection moulding, Polymer shrinkage, Rapid Tooling \& Stereolithography.

\section{Introduction}

Stereolithography (SL) has shown itself to be capable of directly producing tooling cavities (inserts) for injection moulding. The accuracy of the SL process results in epoxy inserts that require few further operations prior to their use in injection moulding. Thus, the process provides a quick route to tooling that, depending on geometric complexity and the moulding polymer, can produce up to approximately 50 parts [1]. Various polymers have been successfully moulded by SL injection moulding. These 
include polyester (PE), polypropylene (PP), polystyrene (PS), polyamide (PA), polycarbonate (PC), polyether-ether-ketone (PEEK), acrylonitrile-styrene-acrylate (ASA) and acrylonitrile-butadiene-styrene (ABS) [2,3,4,5].

SL produces an epoxy mould cavity which possesses very different thermal properties in comparison to metal moulds. Without the use of mould heating or cooling the different mould materials impose very different rates of part cooling due to the inherent heat transfer characteristics of the mould material. Many polymers exhibit different shrinkage according to the cooling conditions of the part during moulding $[6,7,8,9,10,11]$. This work intends to establish the effects of the thermal conditions caused by the mould material on part shrinkage.

\section{Aims}

This research aims to evaluate the shrinkage of mouldings from SL tools in comparison with those from a conventional metal rapid tooling method for injection moulding.

\section{Methodology}

\subsection{Experimental design}

The aim of the experiments was to establish the shrinkage that occurs within 48 hours of the moulding of two polymers of very different characteristics (Polyamide 66 [PA66, crystalline] and Acrylonitrile-Butadiene-Styrene [ABS, amorphous]) when produced by injection moulding in cavities of differing materials (Stereolithography [SL] 
and Aluminium [AL]). This would be by a direct comparison of the dimensions of the moulding cavity and the moulded parts.

Besides the choice of thermoplastic polymer and tool material the shrinkage of an injection moulded part can also be dependent upon several process variables i.e. follow up pressure, machine type etc. However, the only variables in the two experimental sets (PA66 \& ABS) were the tool material type (SL \& AL) and tool cavity geometry (bar \& disc - these were used to identify different shrinkage according to the polymer flow direction during moulding and are further explained in section 3.2). With respect to the injection moulding to be conducted, the only influential variable in each experimental set were the thermal properties of the SL and AL moulding cavities. This dictated the rate at which the heat from the injected polymer would be conducted away from the moulded part through the cavity material. The value of thermal conductivity of the mould materials differ greatly: $\mathrm{SL}=0.2 \mathrm{~W} / \mathrm{m} / \mathrm{K}, \mathrm{AL}=200 \mathrm{~W} / \mathrm{m} / \mathrm{K}$.

\subsection{Mould design}

The mould design was based upon BS EN ISO 294 - 1 \& 4 [12,13] and ASTM D955 [14] standards for establishing shrinkage of injection moulded polymers.

Specimens of two differing geometries were moulded in order to provide shrinkage measurements both parallel (bar shape) and perpendicular (disc shape) to the direction of polymer flow. Dimensioned images of these mould cavities can be viewed in Figure 1. 
The draft angle used to ease part removal from the mould was $1.5^{\circ}$. This value has previously been shown to be an optimum value for reducing potential damage to SL tools upon part ejection [15].

An open gate design was used on both moulds to avoid areas of heat and pressure concentration (such as with fan gating) that can damage an SL tool. This gating system was employed to ensure no great pressure differences in the mould that may have led to unequal stresses in the part and also prevents an interruption to follow up pressure caused by premature freeze-off of the gate. The depth of the gate was the same as the crosssectional thickness of the part (3.2mm in both disc \& bar). The width of the gate size is proportional to the cavity size in each case.

The moulds did not include a part ejection system. The inclusion of steel ejector pins would have provided an area in the moulding cavity which would have cooled the polymer at a different rate than other areas in the mould due the different rates of heat transfer in the immediate areas. Steel is of a much greater thermal conductivity than SL and considerably less than AL. This would not have enabled the experiment to assess the complete effects of the heat transfer provided by SL or AL moulds on part shrinkage. The absence of an ejector system caused no problems as the moulded parts were very simple in shape and were easily removed by hand from the mould.

The SL moulds were manufactured by a 3D Systems SLA350 machine, using Vantico 5190 resin. The build layer thickness was $0.05 \mathrm{~mm}$, as this has previously been demonstrated as an optimal value in extending the working life of SL moulds [16]. 
The inserts were contained within a steel bolster for moulding. These bolsters facilitated alignment on the machine platen, provided material entry into the mould via a tapered sprue bush and protected the inserts from any excessive application of pressure.

\subsection{Tool temperature recording}

In order to establish the heat transfer characteristics that occured in each of the moulds, the temperature was recorded throughout the moulding cycle by the insertion of k-type thermocouples. The tip of the thermocouples were situated such that they were located $0.5 \mathrm{~mm}$ below the surface of the moulding face. The calibration of each individual thermocouple was checked prior to insertion. After insertion into the mould the thermocouples were calibrated to ensure that the temperature $0.5 \mathrm{~mm}$ below the cavity surface was an accurate reflection of the actual cavity surface by comparison of their simultaneous values and their response to temperature change. The difference between the temperatures measured by the thermocouple and the actual surface temperature was never greater than $+/-1^{\circ} \mathrm{C}$. A data acquisition program recorded and logged the temperature profiles over a 10 minute period during the moulding of a part.

\subsection{Injection Moulding}

In order to eliminate extra experimental variables, it was important to find universal parameter values that would work with both the polymers, both the mould geometries and both mould material types. Other than to compensate for the different part volumes of the bar \& disc geometries, the parameters were identical in all the experiments conducted. 
The PA66 used was Bergamid A70NAT produced by PolyOne. The ABS used was Lustran Ultra 2373 produced by Bayer. Both polymers were hygroscopic and were dried immediately prior to processing.

The injection moulding machine used was a Battenfeld 600/125 CDC model with a Unilog 4000 control unit. This machine consisted of a 60 tonne hydraulic clamping unit and a 125x35mm reciprocating screw injection unit with a conventional tapered nozzle.

The following process parameters were used:

- Melt temperature set at $270^{\circ} \mathrm{C}$ in each of the five barrel temperature zones.

- Injection speed set at $100 \mathrm{~mm} / \mathrm{sec}$.

- Injection pressure of 150 bar.

- Follow-up pressure of 150 bar, held for 3 seconds, on a 100mm cushion.

- The ambient temperature of the mould prior to injection was $23.5^{\circ} \mathrm{C}$

- A cooling time of 40 seconds prior to part removal. This was established as the time at which parts could be removed without distortion.

- A clamping force of 15 tonnes.

\subsection{Shrinkage measurement}

BS EN ISO 291 [17] was used as a standard for the environment in which the parts were conditioned and measured 48 hours after moulding. Prior to injection moulding, the mould cavity and later the moulded specimens were measured in the laboratory atmosphere to the nearest $0.01 \mathrm{~mm}$. Twenty parts were moulded from each experimental set and measurements made of each. The parts and cavities were measured across their gauge length. Since the gate for the bar mould was centrally placed at the top 
of the gauge length, two measurements were taken either side of the gate for each part and the cavity. Gauge length measurement for both part \& mould geometries are illustrated in Figure 2. The measurements taken from the specimens were compared to the measurements of the cavities and expressed as a percentage difference of the moulding cavity and the parts in each experimental set after compensation for thermal expansion of the mould.

\section{4. $\quad$ Results}

\subsection{Mould temperature profiles}

The data showed a strong similarity (no greater than $+/-5 \%$ difference) between the temperature profiles for both polymer types (ABS \& PA66) and both cavity geometries (bar \& disc). Very different temperature profiles were experienced by the SL and AL mould types. The similarity between the readings allowed an average plot to be generated that represents the temperature profile for each tool material type (AL \& SL) as shown in Figure 3. The profiles illustrate the vastly different temperature conditions experienced in the SL and AL moulds. The temperature activity in the AL moulds occurred in a very short period of time due to the materials high thermal conductivity. The temperature profile in the SL mould was more extreme and protracted; without external assistance (i.e. cooling by compressed air) the SL mould would take 15 minutes to return to its ambient temperature. 


\subsection{Initial shrinkage results}

The initial shrinkage values, calculated from the part/mould measurements, can be viewed in Table 1. However, these figures need further consideration to establish the total shrinkage that occurs. This is explained in the following section.

\subsection{Compensation for thermal expansion - By calculation}

Both of the mould materials used expand when heated, albeit in differing amounts. The measurements taken for shrinkage must be compensated for by the amount of cavity expansion to establish the true amount of difference between mould and part measurements. Not compensating for thermal expansion could lead to an underestimation of shrinkage that occurs during moulding. The value obtained for shrinkage had to be corrected by an amount corresponding to the thermal expansion of the mould.

The expansion of the mould resulted in an expansion of the cavity, not contraction. This was verified by placing the mould inserts in an oven at a nominal temperature of $50^{\circ} \mathrm{C}$ for 10 minutes and then measuring the cavity in the appropriate measurement axis (see Figure 2). All moulds showed an increase in cavity size, demonstrating an expansion of the cavity. This was authenticated further in later work (section 4.4.5).

This correction factor $\Delta S_{M}$ to the part shrinkage due the mould expansion, is given by:

$$
\Delta \mathrm{S}_{\mathrm{M}}=\alpha \mathrm{m}\left(\mathrm{T}_{\mathrm{m}}-\mathrm{T}_{\mathrm{a}}\right)
$$

where:

$$
\begin{aligned}
& \alpha \mathrm{m}=\text { linear coefficient of expansion of the mould material in } 10^{-6} \mathrm{~m} / \mathrm{m} / \mathrm{K} \\
& \mathrm{T}_{\mathrm{m}}=\text { maximum mould temperature during injection cycle in }{ }^{\circ} \mathrm{C}
\end{aligned}
$$


$\mathrm{T}_{\mathrm{a}}=$ ambient temperature of the mould on the machine in ${ }^{\circ} \mathrm{C}$

The values used were:

$\alpha \mathrm{m}:$

- $\mathrm{SL}=59 \times 10^{-6} \mathrm{~m} / \mathrm{m} / \mathrm{K}$

- $\mathrm{AL}=23.8 \times 10^{-6} \mathrm{~m} / \mathrm{m} / \mathrm{K}$

$\mathrm{T}_{\mathrm{a}}$ :

- $\mathrm{SL}=23.5^{\circ} \mathrm{C}$

- $\mathrm{AL}=23.5^{\circ} \mathrm{C}$

An explanation of these values is given in section 3.4.

$\mathrm{T}_{\mathrm{m}}$ :

These values were derived from the thermal history profiles of the moulds and the injection parameters. The temperature at the end of the injection cycle was used in the calculations as this was the point at which pressure application to the injected polymer ceased. When pressure application ended, so did the period at which the shrinkage could be influenced. Any further expansion of the mould after this period would be unable to affect the part size. The derivation of the values is illustrated in Figure 4. The maximum temperature $\left(T_{m}\right)$ at the end of the injection cycle for each mould type were:

- $\quad \mathrm{SL}$ disc $=57.46^{\circ} \mathrm{C}$

- $\quad \mathrm{SL}$ bar $=44.37^{\circ} \mathrm{C}$

- $\mathrm{AL}$ disc $\&$ bar $=30.39^{\circ} \mathrm{C}$ 
The same maximum temperature was experienced by both the aluminium moulds. This maximum temperature was reached before the end of the injection cycle. The temperature in the stereolithography moulds continued to rise for a long period after completion of the injection cycle. Different maximum temperatures were experienced in the SL disc \& bar moulds due to the different times of the injection cycle required by their different part volume.

Therefore, the calculation for thermal expansion for each mould type was as follows:

SL disc mould

$$
\begin{aligned}
& =59 \times 10^{-6}(57.46-23.5) \\
& =2.00364 \mathrm{~mm} / \mathrm{m} \\
& =0.200364 \%
\end{aligned}
$$

SL bar mould

$$
\begin{aligned}
& =59 \times 10^{-6}(44.47-23.5) \\
& =1.23133 \mathrm{~mm} / \mathrm{m} \\
& =0.123133 \%
\end{aligned}
$$

AL disc \& bar mould

$$
\begin{aligned}
& =23.8 \times 10^{-6}(30.39-23.5) \\
& =0.16422 \mathrm{~mm} / \mathrm{m} \\
& =0.016422 \%
\end{aligned}
$$

The extra amount of shrinkage determined by calculating the expansion of the mould was incorporated into the percentage shrinkage of the measured parts to reveal the compensated total shrinkage. These values are shown in Table 1. However, these 
calculations were slightly simplified. An assumption was made that the whole mould was at the temperature determined by the data acquisition for tool temperatures and as such equal expansion was experienced throughout. In reality the increase in temperature was localised around the moulding cavity. Further work was required to prove whether any differing expansion of the mould cavity occurred due to the temperature distribution and to assess any such effects on the compensation values used.

\subsection{Compensation for Thermal Expansion - by Finite Element Analysis}

Finite Element Analysis (FEA) was used to model the mould expansion due to the localised heating caused by the hot polymer contained within the cavity. The FEA software package used in this work was Algor. Two forms of FEA analysis from Algor were used. Firstly, a transient thermal analysis was conducted in order to determine the temperature distribution in the mould. Then a linear elastic analysis was performed using the temperature distribution results to determine the resulting expansion of the mould cavity.

\subsubsection{FEA modelling. Stage 1 - Creation of model}

The FEA work began with the creation of the required models and FEA mesh. In order to reduce solution time, one quarter of the full mould was created, due to the

quarterly symmetrical nature of each of the specimen's gauge length. This is shown in Figure 5.

The model was extruded such that the mesh spacing between each node was $0.5 \mathrm{~mm}$ in the immediate region beneath the moulding cavity ( 4mm deep) as these are 
the elements of interest when evaluating the cavity expansion. This was conducted to ensure that a node was at the equivalent point to the thermocouple in the experiments, from which the critical time dependant temperatures were derived (see section 3.3). After this the mesh spacing for the rest of the model was $\sim 10 \mathrm{~mm}$ in order to achieve a shorter analysis time.

\subsubsection{FEA modelling. Stage 2 - Allocation of material properties}

The materials were assumed to be homogeneous and isotropic with constant material properties independent of temperature. The values are listed in Table 2.

\subsubsection{FEA modelling. Stage 3 - Transient thermal analysis}

Transient thermal analysis refers to a thermal condition where temperature is a function of time. This analysis type was relevant to the conditions that occurred within the moulds during the experiments. The heat was supplied by the injected polymer which

transferred its energy (heat) into the surrounding mould material. This energy was not limitless and the polymer corresponded by reducing in temperature as the heat was transferred into the lower temperature mould.

To conduct the transient thermal analysis, certain assumptions were made:

- The polymer was all initially at $270^{\circ} \mathrm{C}$ and was in perfect contact with the mould at all times.

- There was no thermal resistance between the plastic and the mould.

- The mould material was all initially at $23.5^{\circ} \mathrm{C}$ 
The critical time dependant temperatures (see Figure 4) at the positions equivalent to thermocouple placement in the experiments were plotted from the FEA results and the correct step in the solution noted. From this temperature distribution it was possible to investigate the reaction of the model (expansion) to a chosen condition (temperature) at a pre-identified time step by performing a linear elastic analysis.

\subsubsection{FEA modelling. Stage 4 - Linear elastic analysis}

The models were fully restrained on the planes of symmetry, on the basis of which the FEA models were devised (shown in Figure 5) and the parting plane of the mould inserts. No further restraints were applied allowing free expansion. The latter point may at first seem a little odd as the mould insert was contained in a steel pocket within the injection moulding bolster. However it has been already shown that even in optimum conditions the maximum possible expansion of the whole insert could be just $\sim 0.25 \mathrm{~mm}$ in any one direction. This amount of expansion could occur freely due to the clearance required to enable fitting and removal of the inserts in the bolster pocket. The planes of restraint are illustrated in Figure 6.

\subsubsection{FEA modelling. Stage 5 - Results}

After the linear elastic analysis was performed the movements (thermal expansion) of the model representing the planes of measurement (see Figure 2) were determined by interrogating the displacement vectors of the nodes representing the cavity edge. An example of this is illustrated in Figure 7. 
From these displacements an average movement (expansion) was determined. In each case the results demonstrated an outwards expansion of the cavity. To determine the total mould expansion over the measurement axis, the average figure derived from the displacement vectors was doubled to include axial expansion in the opposite direction, as only half of the measurement axis was modelled. The results of these expansion values on total part shrinkage are detailed in Table 1.

\section{Discussion}

It can be seen from the results (Table 1) that allowing for thermal compensation reveals higher values of shrinkage in all polymer/tool combinations, albeit at differing scales. Some of the values revealed quite different shrinkage values when the mould expansion was incorporated.

The FEA values gave a good comparison with those derived from the calculations. This gave confidence that the method used did give an accurate assessment of the mould expansion and the resulting total shrinkage of the parts. It should be noted that the FEA method is an approximate solution and relies on the accuracy of the model, mesh density, material properties, surface contact resistance and physical restraints. Although many of the figures used in the FEA were definitive as they were produced from real practice, some were the result of assumptions that had to be made.

When compensation for thermal expansion is included, several themes in the part shrinkage results from the experimental data were revealed. These include: 


\section{Shrinkage direction}

The crystalline polymer (PA66) demonstrated slightly greater shrinkage differences ( 7\%

more) in the polymer flow direction (bar specimen) as opposed to the direction perpendicular to polymer flow (disc specimen). This was also shown with the amorphous (ABS) parts but to a lesser degree ( $\sim 3 \%$ more). These characteristics are typical of all injection moulded parts, with crystalline parts being more susceptible to anisotropy (directional differences) due to the flow direction causing greater alignment of chains within the polymer [19].

\section{Shrinkage according to mould material - PA66}

The results show that the shrinkage that occurred in PA66 parts from the SL moulds of both geometries was double that incurred by the comparative parts from the AL moulds. An expected shrinkage range for PA66 is $1-2.2 \%$ [20]. The parts from the AL moulds demonstrated shrinkage just above the minimum amount expected, while the parts from the SL moulds incurred shrinkage above the maximum in the expected shrinkage range. Also the range of part of sizes measured were much greater than those experienced in the ABS parts. PA66 part measurements differed in a range of $\sim 0.35 \mathrm{~mm}$ as compared to $\sim 0.18 \mathrm{~mm}$ for the ABS parts. This is a typical characteristic of crystalline polymers which are more difficult to hold part tolerances, as compared to amorphous polymers [21]. 


\section{Shrinkage according to mould material - ABS}

The results show that the shrinkage of the ABS parts is largely unaffected by the mould material used. A shrinkage of $\sim 0.76 \%$ was incurred by all ABS parts in the experiments. An expected shrinkage range for ABS is $0.5-0.6 \%$ [20].

\section{Conclusions}

This work has defined that double the amount of shrinkage occurred in PA66 (a crystalline polymer) when injection moulded in an SL tool, as compared to an AL tool. In the same experimental conditions ABS (an amorphous polymer) demonstrated no such differences.

The importance of compensating for thermal expansion of the mould in the calculation of shrinkage has been demonstrated. This is critical in determining absolute shrinkage values in plastic tools, which expand more than metal tools. Neglecting the mould expansion in plastic tools would lead to significant error in determining the absolute part shrinkage.

The establishment of differing part shrinkage in crystalline polymers exposes a flaw in the use of shrinkage compensation factors supplied by manufacturers. This work has shown that the shrinkage of crystalline polymers is dependant upon process conditions which are variable. Supplied shrinkage factors would be specific only to the conditions under which the test pieces were produced. Thus, traditional shrinkage factors are insufficient not only in the use of SL tools, but also any other techniques where there is any significant process variation from the 'norm'. 
It has been shown that the shrinkage of an amorphous polymer was unaffected by the cooling conditions which were imposed by mould material type. Consequently, where possible, it is recommended that amorphous polymers are used in preference to crystalline alternatives when using SL moulds.

\section{References}

[1] Hilton, P.D \& Jacobs, P.F., 2000, Rapid Tooling: Technologies and Industrial Applications, (Marcel Dekker), ISBN 0-8247-8788-9.

[2] Luck, T., Baumann, F. \& Baraldi, U., 1995, Comparison of downstream techniques for functional and technical prototypes- fast tooling with RP, Proceedings of $4^{\text {th }}$ European RP Conference, $13^{\text {th }}-15^{\text {th }}$ June, Belgriate, Italy, pp $247-260$.

[3] Eschl, J., 1997, Experiences with photopolymer inserts for injection moulding, European Stereolithography Users Group meeting, $2^{\text {nd }}-5^{\text {th }}$ November, Florence, Italy. [4] Harris, R. A., 2002, Direct AIM tooling. Rapid Prototyping \& Tooling State of the Industry Annual Worldwide Progress Report. Wohlers Report 2002, Published by Wohlers Associates Inc, USA, Part 3: Tooling, Page 70.

[5] Schulthess, A., Steinmann, B. \& Hofmann, M., 1996, Cibatool ${ }^{\mathrm{TM}}$ SL Epoxy Resins and Some New Applications, Proceedings of the 1996 North American Stereolithography Users Group Meeting, March 10 - 14, San Diego, USA.

[6] Damle, M., Mehta, S., Malloy, R., McCarthy, S., 1998, Effect of Fibre Orientation on the Mechanical Properties of an Injection Molded part and a Stereolithography-Insert Molded Part, Proceedings of the society of plastics engineers (SPE) annual technical conference (ANTEC), Atlanta, USA, pp 584 - 588. 
[7] Velarde, D. A. \& Yeagley, M. J., 2000, Linear Shrinkage Differences in Injection Moulded Parts. Plastics Engineering, The Society of Plastics Engineers, December 2000, pp $60-64$.

[8] Gipson, P., Grelle, P., \& Salamon, B., 1999, The effects of process conditions, nominal wall thickness, and flow length on the shrinkage characteristics of injection molded polypropylene, The journal of injection molding technology, v3, n3. pp 117-125. [9] Patel, P., 1997, Effect of Processing Conditions on the Shrinkage and Crystallinity of Injection Moulded Parts, Proceedings of the society of plastics engineers (SPE) annual technical conference (ANTEC), Toronto, Canada, pp 3632-3635.

[10] Tursi, D. \& Bistany, S. P., 2000, Process and Tooling Factors Affecting Sink Marks for Amorphous and Crystalline Resins, Journal of Injection Molding Technology, September, Vol 4, No 3, pp 114 - 119.

[11] Pierick, D. \& Noller, R., 1991, The Effect of Processing Conditions on Shrinkage. Proceedings of the society of plastics engineers (SPE) annual technical conference (ANTEC), Montreal, Canada, pp 252 - 253.

[12] BS EN ISO 294 - 1, 1998, Plastics - Injection moulding of test specimens of thermoplastic materials - Part 1: General principles, and moulding of multipurpose and bar test specimens, British Standards Institution, Issue 2, ISBN 0580272990.

[13] BS EN ISO 294 - 4, 1998, Plastics - Injection moulding of test specimens of thermoplastic materials - Part 4: Determination of moulding shrinkage, British Standards Institution, Issue 2, ISBN 0580278263. 
[14] ASTM D955, 1996, Standard test method for measuring shrinkage from mold dimensions of molded plastics, American Society for Testing and Materials.

[15] Harris. R.A, Hopkinson. N, Newlyn. H, Hague. R \& Dickens, P.M., 2002, Layer thickness and draft angle selection for stereolithography injection mould tooling, International Journal of Production Research, Volume 40, No 3, $15^{\text {th }}$ February 2002, Pages 719 - 729, ISSN 0020-7543.

[16] Harris, R. A., Newlyn, H. .A, and Dickens, P. M., 2002, The Selection of Mould Design Variables in Direct Stereolithography Injection Mould Tooling, Journal of Engineering Manufacture, IMechE proceedings part B, Vol 216, No B4, ISSN 09544054. pp $499-505$.

[17] BS EN ISO 291, 1997, Plastics - Standard atmospheres for conditioning and testing, British Standards Institution, ISBN 0580285855.

[18] Machine Design, 1993, 1994 Materials Selector Issue. Vol. 65, No. 26, December, Penton Publishing Inc.

[19] Birley, A.W., Heath, R.J. \& Scott, M.J., 1988, Plastics Materials: Properties and Applications, $2^{\text {nd }}$ Edition, (Blackie \& Son Limited), ISBN 0-216-92489-8.

[20] Belofsky, H., 1995, Plastics: Product Design and Process Engineering, (Carl Hanser Verlag), ISBN 1-56990-142-2.

[21] Bryce, D.M., 1997, Plastic Injection Moulding...material selection and product design fundamentals (Society of Manufacturing Engineers), ISBN 0-87263-488-4.

[22] MatWeb, The Online Material Information Resource Homepage. http://www.matweb.com/index.asp?ckck=1

[23] Munday, A. J. \& Farrar, R. A., 1979, An Engineering Data Book, (Macmillan Press Ltd), ISBN 0333258290. 


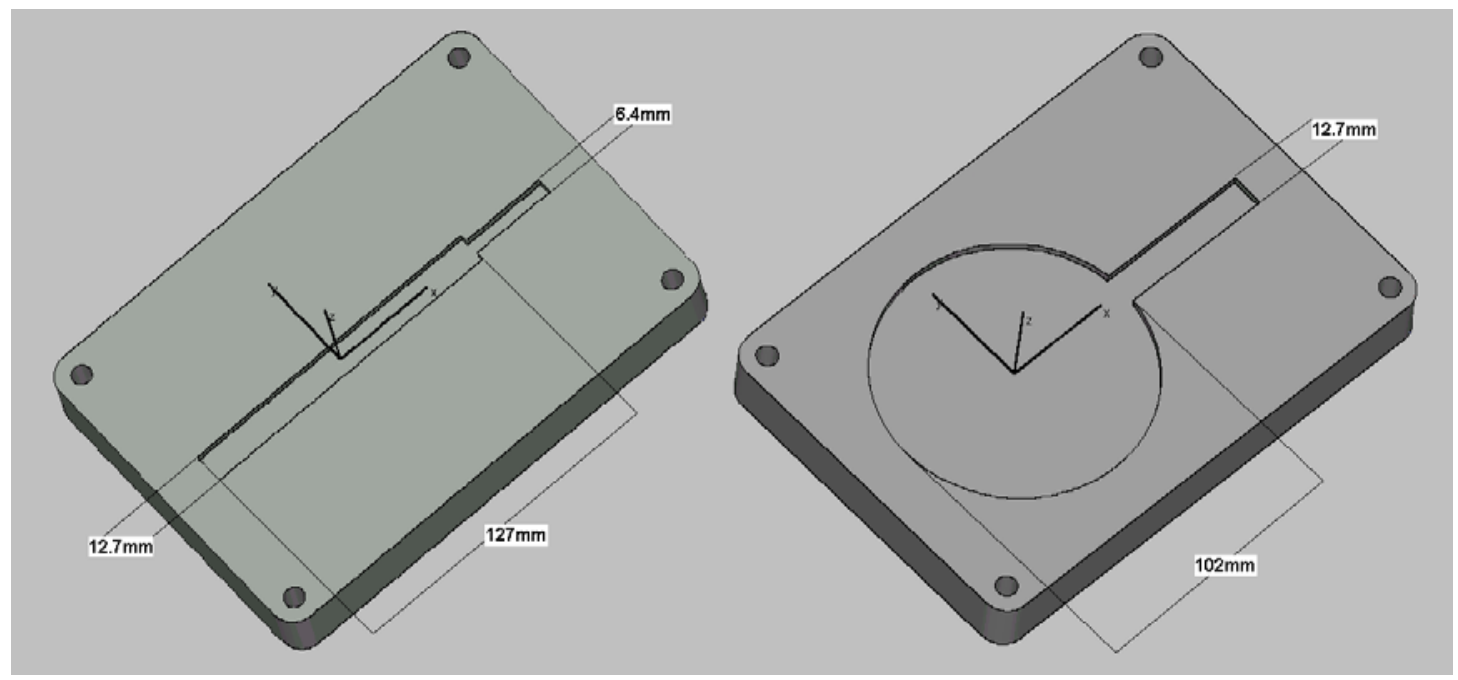

Figure 1
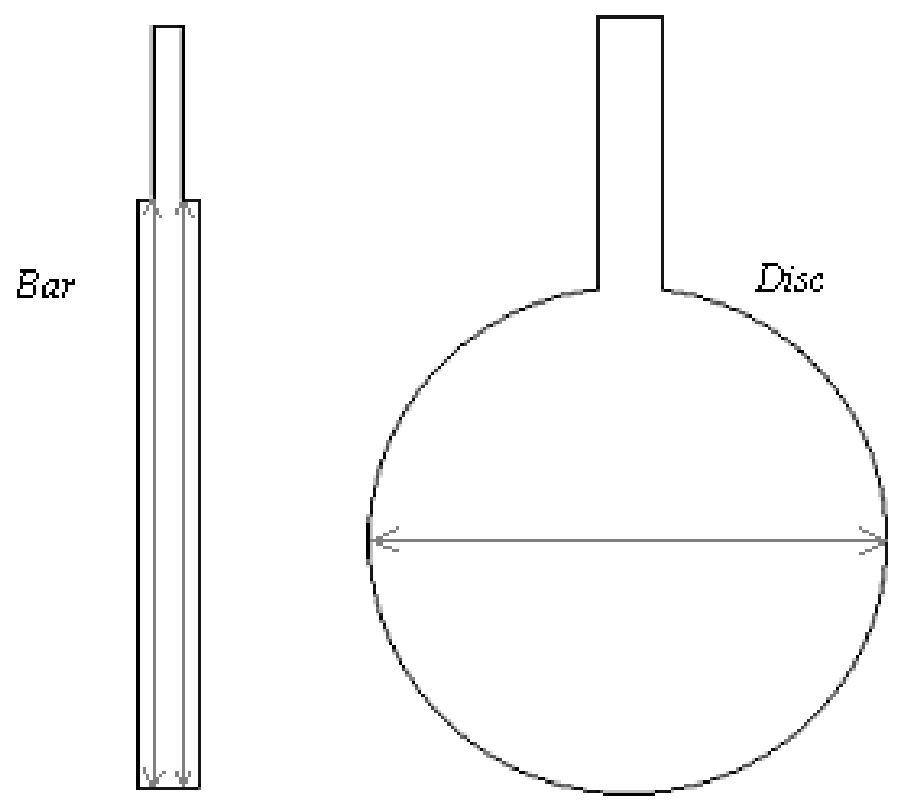

Figure 2 


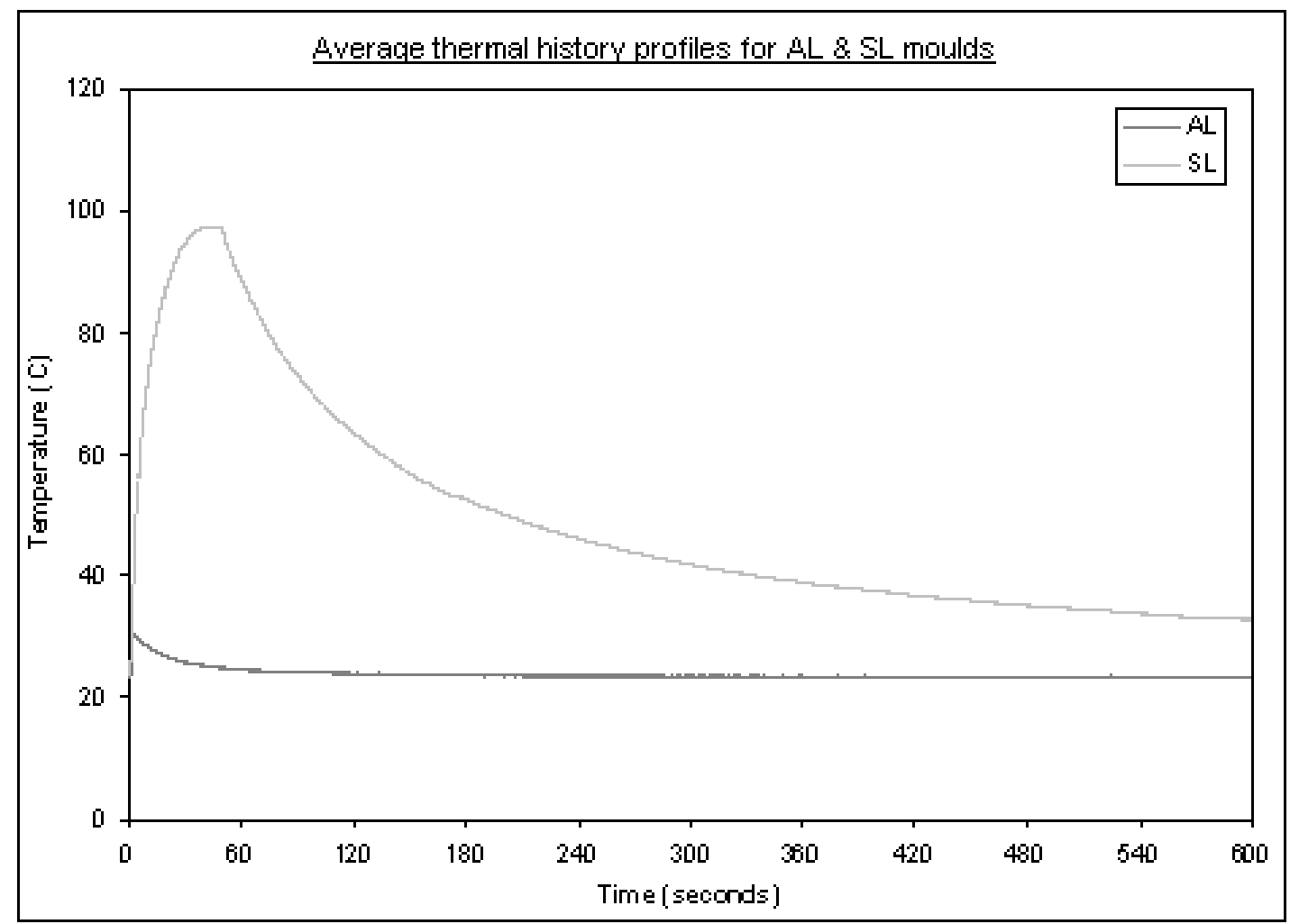

Figure 3

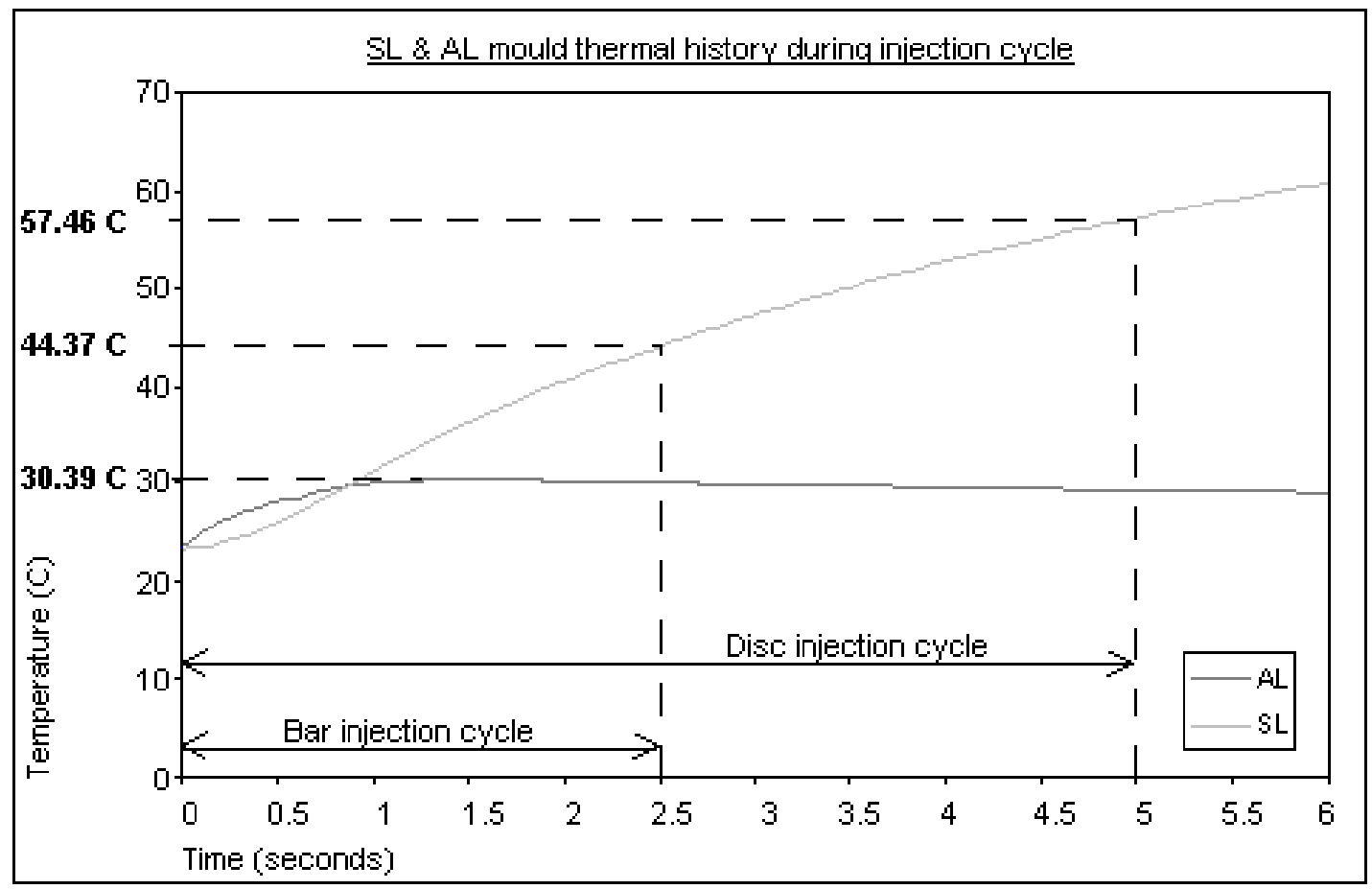

Figure 4 


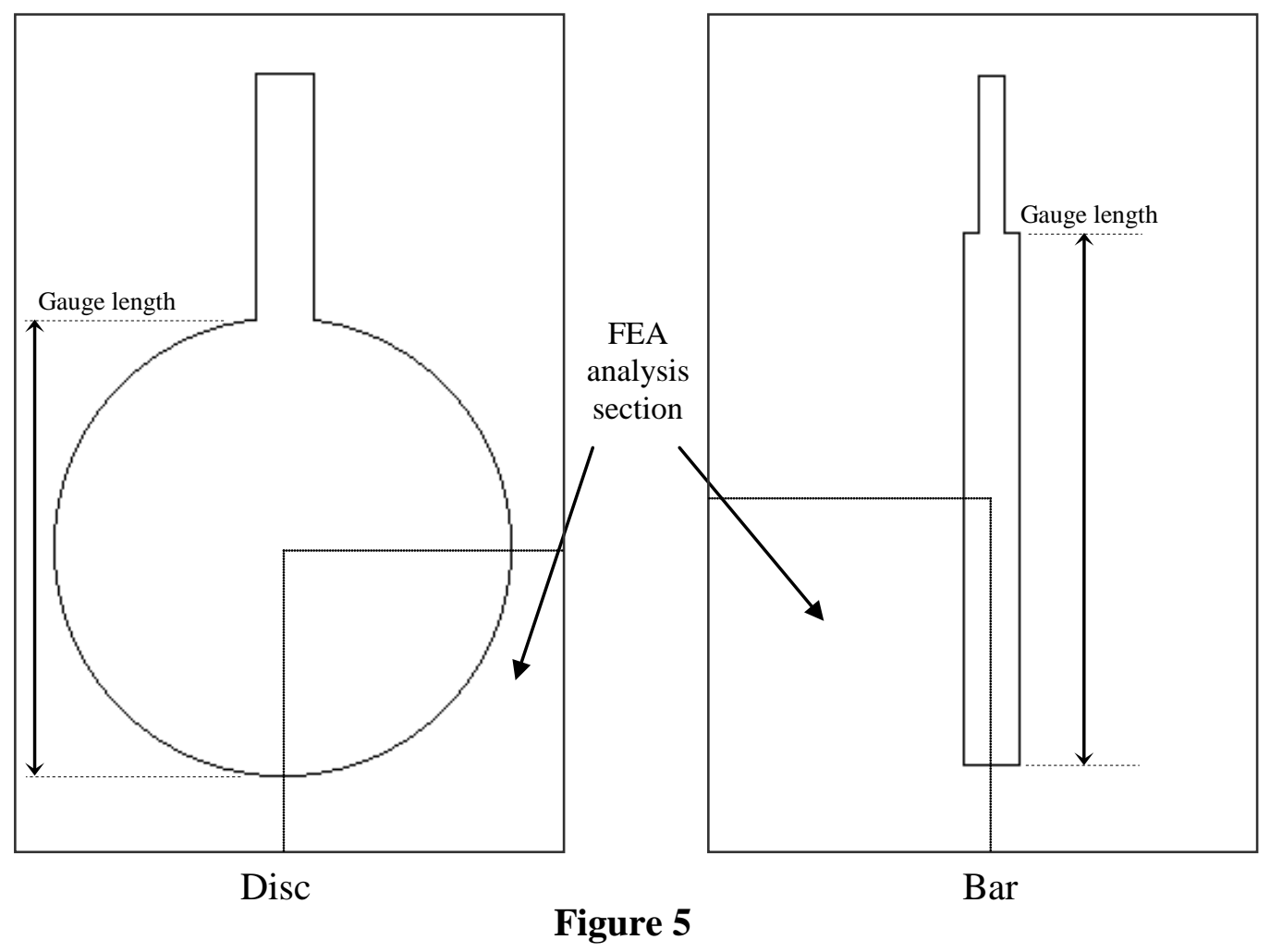




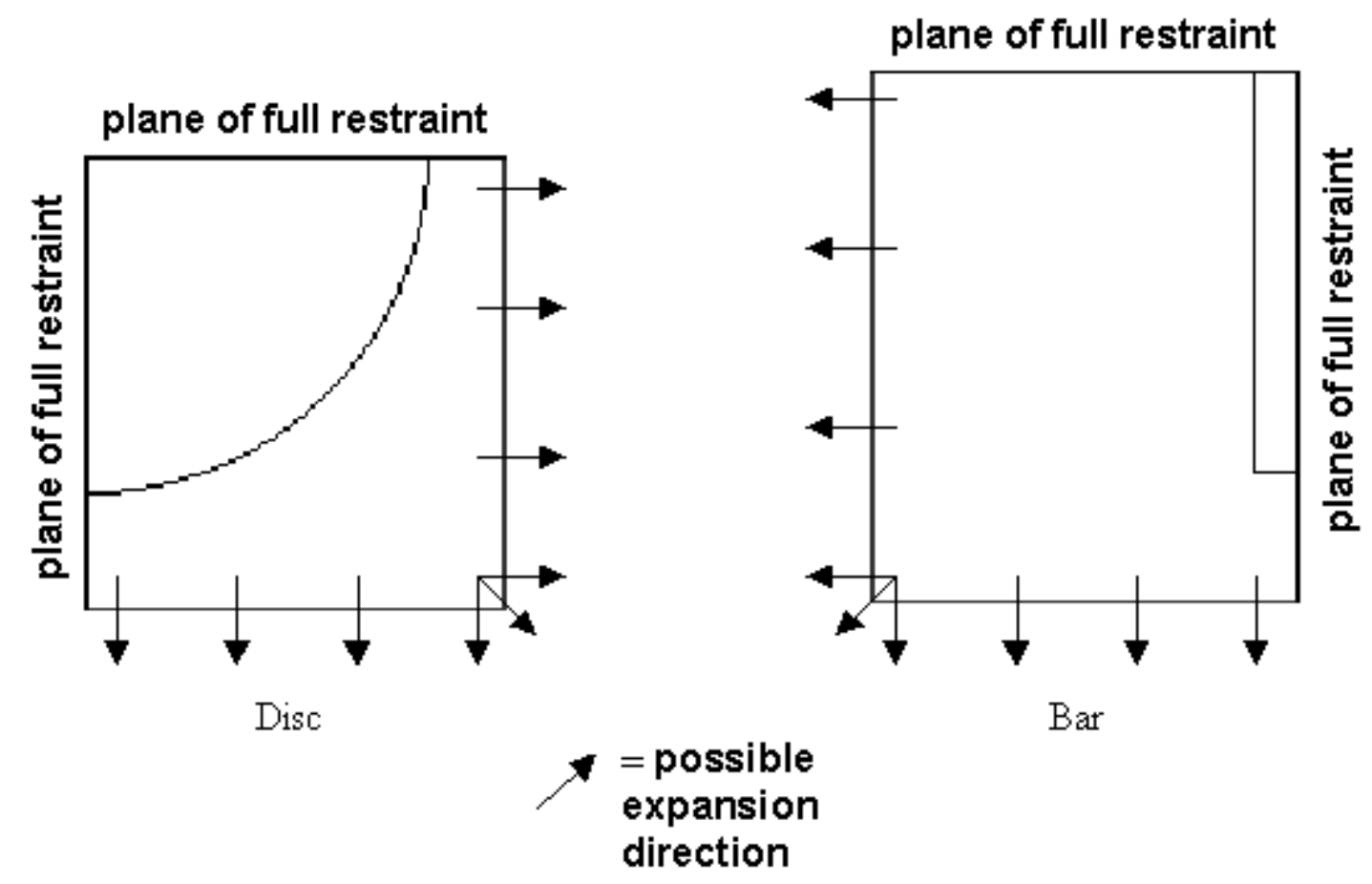

Figure 6 


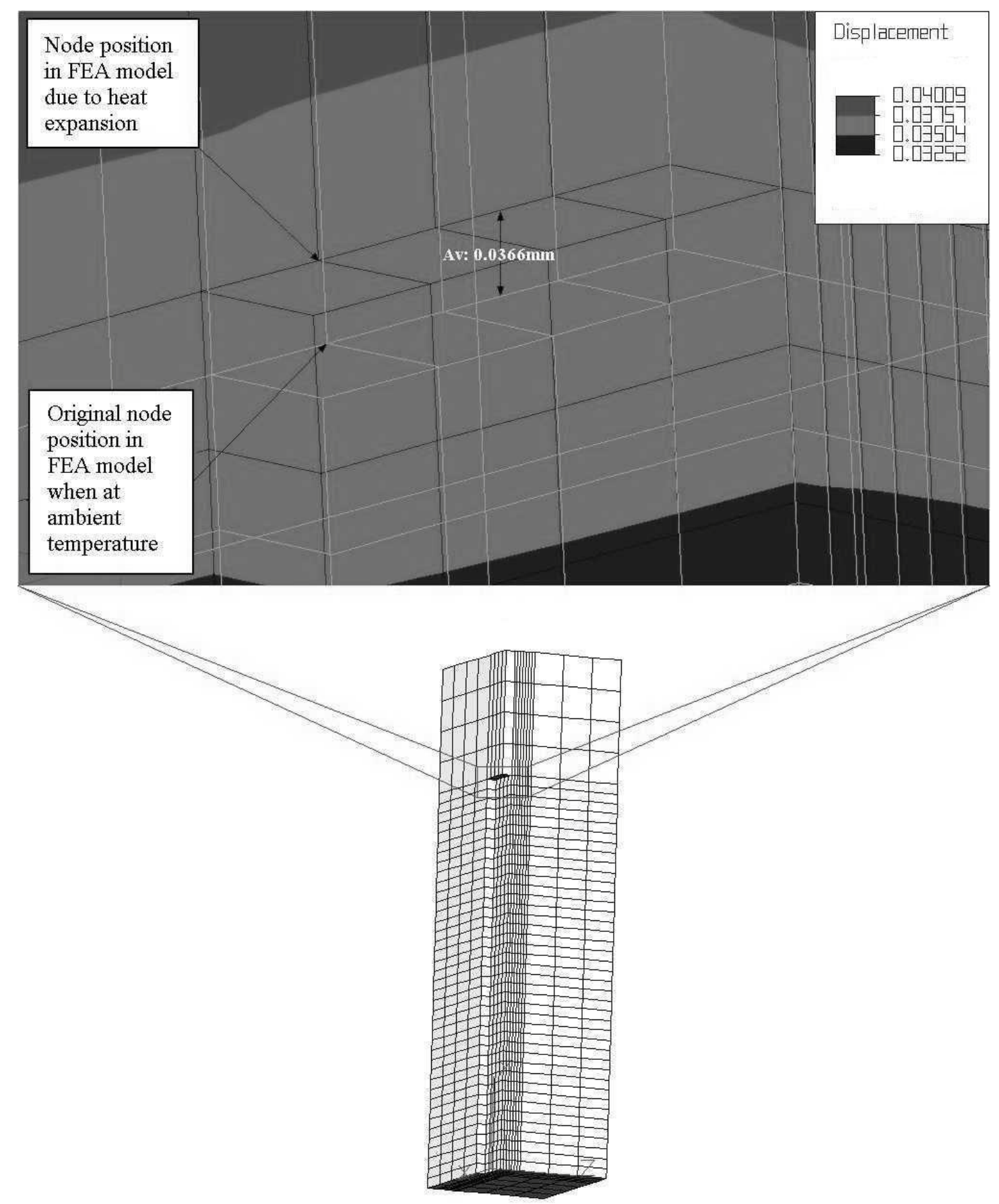

Figure 7 


\begin{tabular}{|l|l|l|l|l|l|l|l|l|}
\hline & \multicolumn{3}{|c|}{ PA66 Part measurement } & \multicolumn{3}{c|}{ ABS Part measurement } \\
\hline Mould type & AL bar & SL bar & AL disc & SL disc & AL bar & SL bar & AL disc & SL disc \\
\hline $\begin{array}{l}\text { \% part/mould } \\
\text { difference }\end{array}$ & -1.3272 & -2.611 & -1.2177 & -2.4149 & -0.7524 & -0.6474 & -0.7351 & -0.5611 \\
\hline $\begin{array}{l}\text { \% part/mould } \\
\text { difference } \\
\text { including } \\
\text { compensation } \\
\text { for thermal } \\
\text { expansion by } \\
\text { calculation }\end{array}$ & -1.3434 & -2.7308 & -1.2339 & -2.6101 & -0.7687 & -0.7696 & -0.7514 & -0.7599 \\
$\begin{array}{l}\text { \% part/mould } \\
\text { difference } \\
\text { including } \\
\text { compensation. } \\
\text { for thermal } \\
\text { expansion by } \\
\text { FEA }\end{array}$ & -1.3841 & -2.7447 & -1.2712 & -2.5649 & -0.8097 & -0.7837 & -0.7887 & -0.7139 \\
\hline
\end{tabular}

Table 1 


\begin{tabular}{|c|c|c|}
\hline Epoxy & SI units & Reference source \\
\hline$\rho$ (density) & $1250 \mathrm{~kg} / \mathrm{m}^{3}$ & [22] \\
\hline K (thermal conductivity) & $0.19 \mathrm{~W} / \mathrm{m}^{0} \mathrm{~K}$ & [22] \\
\hline $\mathrm{C}_{\mathrm{p}}$ (specific heat capacity) & $1046.7 \mathrm{~J} / \mathrm{kg}^{\circ} \mathrm{C}$ & [22] \\
\hline E (modulus of elasticity) & $2.6 \times 10^{9} \mathrm{~N} / \mathrm{m}^{2}$ & [22] \\
\hline$v$ (poissons ratio) & 0.35 & [22] \\
\hline$\alpha$ (thermal coefficient of expansion) & $59 \times 10^{-6} /{ }^{0} \mathrm{C}$ & [18] \\
\hline \multicolumn{3}{|l|}{ Aluminium } \\
\hline$\rho$ & $2720 \mathrm{~kg} / \mathrm{m}^{3}$ & [23] \\
\hline K & $170 \mathrm{~W} / \mathrm{m}^{\circ} \mathrm{K}$ & [23] \\
\hline $\mathrm{C}_{\mathrm{p}}$ & $880 \mathrm{~J} / \mathrm{kg}^{\circ} \mathrm{C}$ & [23] \\
\hline $\mathrm{E}$ & $68.9 \times 10^{9} \mathrm{~N} / \mathrm{m}^{2}$ & [23] \\
\hline$v$ & 0.3 & [23] \\
\hline$\alpha$ & $23 \times 10^{-6} /{ }^{0} \mathrm{C}$ & [23] \\
\hline \multicolumn{3}{|l|}{ Polymer } \\
\hline$\rho$ & $1145 \mathrm{~kg} / \mathrm{m}^{3}$ & [22] \\
\hline K & $0.2962 \mathrm{~W} / \mathrm{m}^{0} \mathrm{~K}$ & [22] \\
\hline $\mathrm{C}_{\mathrm{p}}$ & $1625.7 \mathrm{~J} / \mathrm{kg}^{\circ} \mathrm{C}$ & [22] \\
\hline $\mathrm{E}$ & $0.26 \times 10^{9} \mathrm{~N} / \mathrm{m}^{2}$ (see note) & (see note) \\
\hline$v$ & 0.35 & [22] \\
\hline$\alpha$ & $\begin{array}{c}59 \text { or } 23 \times 10^{-6} /{ }^{\circ} \mathrm{C} \text { (see } \\
\text { note) }\end{array}$ & [18] or [23] \\
\hline
\end{tabular}


Note - The value of E for the polymer was a nominal low value to reduce restraint. The value of $\alpha$ in the polymer was made the same as the mould material to prevent interference. The use of such values in both cases was to ensure that the presence of the polymer did not influence the expansion of the cavity in the simulation.

\section{Table 2}

Figure 1 - CAD images of the mould cavity designs

Figure 2 - Measurement positions for disc \& bar geometries

Figure 3 - Average temperature profiles for AL \& SL moulds

Figure 4 - Thermal conditions in the moulds during injection cycle

Figure 5 - FEA model section of bar \& disc moulds

Figure 6 - Planes of restraint on bar \& disc FEA models

Figure 7 - Interrogation of displacement vectors in FEA results to establish amount of expansion - example shows AL bar

Table 1 - The \% size difference of part/mould, including compensation for thermal expansion by calculation \& FEA.

Table 2 - Material values used in FEA for Epoxy, Aluminium \& Polymer 